\title{
viewpoint
}

\section{Sciencefact and the SEN S agenda}

What can wereasonably expect from ageing research?

\author{
H uber Warner ${ }^{+}$, JulieAnderson ${ }^{1}$, Steven Austad², Ettore Bergamini ${ }^{3}$, D ale Bredesen ${ }^{1}$, Robert Butler ${ }^{4}$, \\ Bruce A. Carnes ${ }^{5}$, Brian F. C. Clark ${ }^{6}$, Vincent Cristofalo ${ }^{7}$, John Faulkner ${ }^{8}$, Leonard Guarente9, \\ David E. Harrison ${ }^{10}$, Tom Kirkwood ${ }^{11}$, Gordon Lithgow ${ }^{1}$, George M artin ${ }^{12}$, Ed M asoro ${ }^{2}$, Simon M elov', \\ Richard A. M iller ${ }^{8}$, S. Jay O Ishansky ${ }^{13}$, Linda Partridge ${ }^{14}$, Olivia Pereira-Smith ${ }^{2}$, Tom Perls ${ }^{15}$, \\ Arlan Richardson ${ }^{2}$,JamesSmith ${ }^{2}$, Thomasvon Zglinidki ${ }^{11}$, Eugenia Wang ${ }^{16}$,JeanneY. Wei ${ }^{17} \&$ T.Franklin Williams ${ }^{18}$
}

n $n$ an article published in the $\mathrm{EMBO}$ reports Special Issue on Time and Ageing, Aubrey D.N.J. de Grey criticizes biogerontologists for what he sees as their generally pessimistic view of the possibilities for intervening in the ageing process (de Grey, 2005). In his view, "resistance [of biogerontologists] to debate on how to postpone ageing is delaying progress and costing lives." de Grey believes he has formulated a research plan that, in his words, will "stop people from getting frailer and more prone to life-threatening diseases as they get older, and moreover [will] restore the already frail to youthful vitality". Similar to vintage cars maintained by careful mechanics, individuals will then retain this happy state "indefinitely ... even at ages many times what we reach today". In de Grey's opinion, "the failure of most biogerontologists to maintain an open mind concerning the scientific options ... [has] the result that much longer healthy lives are being denied those who will die before 'real anti-aging medicine' arrives."

In the words of the great American journalist H.L. Mencken, "for every complex problem, there is a simple solution, and it is wrong." de Grey's research programme, which he terms 'strategies for engineered negligible senescence' (SENS), involves a combination of preventative and therapeutic interventions (de Grey, 2003). To solve the problem of apoptosis in senescent cells, one simply uses "senescence marker-tagged toxins". To cure cancer, one just calls on "total telomerase deletion plus cell therapy". To prop up the failing immune system, one can turn on "IL-7 mediated thymopoiesis". To reverse mitochondrial mutations, one need only use "allotopic [mitochondrial]-coded proteins" of the type favoured by algae. Cell replacement can be accomplished by "stem cell therapy and growth factors", whereas retooling the endocrine system relies on "genetically engineered muscle". Cleavage of glycosylation crosslinks will involve periodic exposure to phenacyldimethylthiazolium chloride, and so on. Yet, in his writings, de Grey fails to mention that none of these approaches has ever been shown to extend the lifespan of any organism, let alone humans.

The response to this farrago- "a confused mixture, or hodgepodge"-depends on one's perspective. Journalists with papers to sell or air-time to fill too often fall for the idea of a Cambridge scientist who knows how to help us live forever with telomerase, allotopic mitochondrial-coded proteins and marker-tagged toxins. To explain to a layman why de Grey's programme falls into the realm of fantasy rather than science requires time, attention and the presentation of detailed background information. In addition, anyone who is tempted to do so is easily cast as a Luddite, an enemy of creativity and noble ambition, and someone whose prissy reluctance to confront de Grey's ideas might prevent us from living forever.

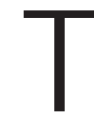
hose who work in science or know a good deal about how science progresses understand how difficult it is to select, among many attractive ideas, the few that might actually pan out. It is equally difficult to follow good leads painstakingly, while avoiding false hopes, as scientific knowledge matures to the point where engineering ideas present themselves for test. Those among us who are immunologists recognize that the few tests of the idea that interleukin 7 (IL-7) can improve protective immunity have produced disappointing results so far. Learning how to integrate IL-7 into preventive medicine will take decades of hard work, if it ever proves to be useful. Similarly, those of us who work on cancer know that the inhibition of telomerase is one among many interesting ideas that might, one day, help to control some forms of human neoplasia. However, we also know that the ablation of telomerase activity might have serious side effects on stem-cell and lymphocyte function, might fail to work in some tumour types, might select for neoplastic cells with alternative ways to avoid growth inhibition, and has not yet been shown to prevent or treat cancer either in humans or in animal models. Genetically engineered muscle cells might one day prove useful as sources of needed hormones or systemic factors, but the use of such an approach to slow ageing, let alone to reverse it, must confront the plain fact that,

Journalists... too often fall for theidea of a Cambridge scientist who knows how to help us live forever with telomerase, allotopic mitochondrial-coded proteins and marker-tagged toxins 
at present, no one knows which hormonal changes might be needed, in what tissues and at what intervals, to accomplish such a miracle. As far as we know, "senescence marker-tagged toxins" do not yet exist. Moreover, if they did, it is uncertain whether they would do more harm than good. Most therapeutic ideas, even the most plausible, come to nothing-in pre-clinical studies or clinical research, the proposed interventions are found to be toxic or induce unwelcome side effects, are mooted by more successful ideas, or, most often, simply fail to work as hoped.

\section{Each one of the specific proposals that comprise the SENS agenda is, at our present stage of ignorance, exceptionally optimistic}

Each one of the specific proposals that comprise the SEN S agenda is, at our present stage of ignorance, exceptionally optimistic. Therefore, by multiplying the probabilities of success, the claim that all of these proposals can be accomplished, although presented with confidence in de Grey's writings, seems nonsensical. Consequently, the idea that a research programme organized around the SENS agenda will not only retard ageing, but also reverse it-creating young people from old ones-and do so within our lifetime, is so far from plausible that it commands no respect at all within the informed scientific community.

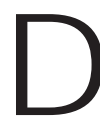

eciding on priorities for scientific research requires the careful weighing of alternatives so as to assess their relative merits, possible weaknesses, anticipated rewards and costs. All of us who have signed this essay agree with de Grey that research into the basic biology of ageing needs and deserves more support than it presently receives. In our opinion, those who are in charge of deciding how research funds are allocated seriously underestimate the potential benefits of basic research on the causes of ageing in terms of public health. We believe that we have good solid arguments on these points, and ideas and evidence that deserve public hearing (Miller, 2002). The fact that the rate of ageing is malleable by evolutionary pressures, which can slow ageing dramatically by selecting among genetic variants in suitable

\section{... those who arein charge of deciding how research funds are allocated seriously underestimate thepotential benefits of basic research on thecauses of ageing in terms of public health}

ecological niches, provides a rationale for thinking that we might eventually learn how to postpone human illnesses to an important degree. Some of us feel that research on telomere biology deserves special attention; others would argue that studies of mitochondrial function merit high priority and still others believe that the evaluation of antioxidant defences might be fruitful. We are all familiar with the unambiguous evidence from numerous laboratories showing that ageing can be slowed sufficiently to increase longevity by 30 or $40 \%$ in mammals. Moreover, we believe that learning how to do similar things for humans might lead to impressive improvements in public health, with extra decades of active diseasefree lifespan as a plausible, although by no means certain, goal. Some of us are moderately optimistic that present ageing research will have therapeutic implications, whereas others are less optimistic on this point. None of us, how ever, believes that plans to 'engineer' the body to prevent ageing indefinitely or to turn old people young again have the remotest chance of success. Although it is foolhardy to try to 'prove' that a particular engineering problem can never be solved, we can and must insist that speculation based on evidence be discriminated from speculation based on wish fulfilment alone, and recommend that research programmes should be based on fact and extrapolation from earlier successes and failures.

Selecting the most promising lines of scientific investigation from among many possibilities is the key to doing good science. It is the hardest thing that a graduate student or postdoctoral fellow has to learn, and many never do. Each successful investigator knows, from hard experience, that his or her 'hit' rate- the proportion of ideas that leads to major discoveries-is relatively low. Each idea that we decide to pursue will cost years of work and a great deal of money, so we spend a lot of time- at meetings, seminars and in the library-trying to search for and weigh alternatives, and looking for loopholes in our chain of arguments before they are pointed out to us either by peer review ers or experimental results.
Short-circuiting this process of critical, sceptical selection among research priorities- presenting buzzwords as substitutes for carefully selected and testable hypotheses about ageing and its control-might be clever marketing, but it is a poor substitute for scientific thought. Presented by an articulate, witty and colourful proponent, a flashy research agenda might catch the eye of a journalist or meeting organizer who is hunting for attention, publicity and an audience; however, the SEN S agenda is easily recognized as a pretence by those with scientific experience.

When does such a promotion campaign make the transition from an amusing eccentricity to an obstacle to scientific progress? Ageing research is a discipline that is only just emerging from a reputation for charlatanry. Indeed, those who represent themselves as vendors of amazing miracle cures for ageing are more numerous, and attract far more public interest, than those who carefully research the causes and potential retardation of the ageing process. This has implications for the pursuit and funding of research. Although politicians know that they can earn votes by promising cures for cancer and AIDS, a politician who was rash enough to campaign on a pledge to slow the ageing process would be judged as lunatic. This is unfortunate, as many of us who work on ageing believe our work is likely, if properly supported, to produce improvements in public health at least equal to those that would come from a vaccine for AIDS or a cure for cancer. Nevertheless, we are gradually-much too gradually-gaining the respect and attention of pundits, journal editors, peer reviewers, scientific administrators, and even the occasional politician who is willing to consider the implications of our research for preserving health and postponing disease. From this hard-won perspective, we are concerned when we see scientific journals and meetings give space and attention to empty fantasies of immortality, artfully camouflaged under the guise of research proposals.

d e Grey's most recent challenge takes the form of a chiding lament over the resistance of mainstream biogerontologists to 'debate' his plan on its merits. On its face, this appeal earns sympathy points. Who could be opposed to a free exchange of ideas? What authoritarian Philistine would endorse censorship 
or the quashing of different points of view, no matter how odd they might seem to contemporary conservative opinion? Surely the publicity drawn to ageing research by the SENS/de Grey juggernaut will, in the long run, draw attention to, and support for, all forms of ageing research through a kind of 'trickle-up' mechanism? Why not simply debate with de $\mathrm{G}$ rey and let the most convincing arguments win? It is, however, our opinion that pretending that such a collection of illfounded speculations is a useful topic for debate, let alone a serious guide to research planning, does more harm than good both for science and for society.

\section{Short-circuiting [the] process of critical, sceptical selection among research priorities... [that is] presenting buzzwords as substitutes for carefully selected and testable hypotheses about ageing... might beclever marketing, but it is a poor substitute for scientific thought}

Richard Dawkins has considered a related problem: should biologists engage in public debates with creationists on the relative merits of $D$ arwin's theory of evolution versus biblical 'theories' about the origin of species? Dawkins argues that engaging in such jousting contests might be a bad idea, in that such spectacles create, in the arena of public opinion, the misleading impression that biologists consider the 'arguments' of creationists sufficiently meritorious to require public discussion (Dawkins, 2003). Of course, unlike the creationists, de Grey's SENS agenda does not threaten to undermine a central scientific theory or aim to mute opposing theories in schools and in public; however, there are similarities that are worthy of consideration. Treating arguments and proposals that are not backed up by scientific evidence as though they were scientific ideas carries the risk of making them impressive to laypersons, whose main way of distinguishing among hypotheses is to take note of those that are promoted in public media or presented to them by advocates whose style they like. A conference devoted to public transport systems would not be tempted to include a debate on teleportation as an approach to reduce traffic congestion; neither would an editor assembling a special issue on food shortages in the developing world solicit an essay on Aladdin's lamp.

\section{There are good reasons why science tends to award more points for testable ideas than for ill-defined speculations, and more points for results than for ideas alone}

Dawkins points out that the scientific community has developed a better way to discriminate among competing ideas: testing them experimentally (Dawkins, 2003). If de $\mathrm{Grey}$ believes that he has a good strategy to reverse the ageing process, he should devise a detailed plan for testing his ideas, and then, like the rest of us, convince sponsors that his project deserves funding. If he and his colleagues produce scientific evidence that some aspects of ageing can be reversed by a judicious mixture of phenacyldimethylthiazolium chloride, marker-tagged toxins and IL-7, we promise that we will be impressed.

There are good reasons why science tends to award more points for testable ideas than for ill-defined speculations, and more points for results than for ideas alone. Science- unlike fantasy-works and leads to discoveries that serve as the foundation for material progress. Creative testable ideas are the lifeblood of scientific progress. In our opinion, however, the items of the SENS programme in which de Grey expresses such blithe confidence are not yet sufficiently well formulated or justified to serve as a useful framework for scientific debate, let alone research. de G rey's credibility, among those who do not know his ideas well enough to understand their weaknesses, lies partly in his claims that his ideas have been judged interesting and provocative by mainstream gerontologists. The authors of this article, proud of our roles as representative mainstream biogerontologists, wish to dissociate ourselves from the cadre of those impressed by de Grey's ideas in their present state.

Modern biogerontology is blessed with exciting new results, new ideas and new hopes for progress, initially in the laboratory and later in the clinic. It is time to draw public attention to these accomplishments and prospects, and to develop public support for this research area as it moves from its stigmatized past to a future in which biogerontological findings could serve as a keystone of preventive medicine. Helping the public discriminate between science and science fiction is an important step towards this objective.

\section{REFEREN CES}

Dawkins R (2003) A Devil's Chaplain: Reflections on Hope, Lies, Science, and Love. Boston, M A, USA: Houghton Mifflin

de Grey AD (2003) The foreseeability of real antiaging medicine: focusing the debate. Exp Gerontol 38: 927-934

de Grey AD (2005) Resistance to debate on how to postpone ageing is delaying progress and costing lives. EMBO Rep 6: S49-S53

Miller RA (2002) Extending life: scientific prospects and political obstacles. Milbank Q 80: 155-174

+Corresponding author. Huber Warner is Associate Dean for Research at the University of Minnesota College of Biological Sciences, St Paul, MN, USA.

E-mail: warne033@umn.edu

'Buck Institute for Age Research, Novato, CA, USA; ${ }^{2}$ University of Texas Health Science Center, San Antonio, TX, USA; ${ }^{3}$ University of Pisa, Pisa, Italy; ${ }^{4}$ International Longevity Center, New York, NY, USA; ${ }^{5}$ The University of O klahoma Health Sciences Center, Tulsa, OK, USA $;{ }^{6}$ D epartment of Molecular Biology, Aarhus University, D enmark; ' Lankenau Institute for Medical Research, Wynnewood, PA, USA; 'University of Michigan, Ann Arbor, MI, USA; $9 M$ assachusetts Institute of Technology, Cambridge, MA, USA; ${ }^{10}$ The Jackson Laboratory, Bar Harbor, ME, USA; ${ }^{11}$ University of Newcastle upon Tyne, N ewcastle upon Tyne, UK; ${ }^{12}$ D epartment of Pathology, University of Washington, Seattle, WA, USA; ${ }^{13}$ University of Illinois at Chicago, Chicago, IL, USA;

${ }^{14}$ University College London, London, UK; ${ }^{15}$ University of Boston, Boston, MA, USA; ${ }^{16}$ University of Louisville, Louisville, KY, USA; ${ }^{17}$ University of Arkansas for Medical Sciences, Little Rock, AR, USA; ${ }^{18}$ University of Rochester, Rochester, NY, USA

doi:10.1038/sj.embor.7400555

Related article:

Aubrey D.N.J. de Grey's response to this viewpoint appears as a Correspondence in this issue. See page 1000 for 'Likeit or not, life-extension research extends beyond biogerontology'. 